Abstracta Iranica

Revue bibliographique pour le domaine irano-aryen

Volume 42-43 | 2021

Comptes rendus des publications de 2019-2020

\title{
Harald Suermann. „Thomas-Christen von Indien und Rewardashir"
}

\section{Christelle Jullien}

\section{(2) OpenEdition}

Journals

Édition électronique

URL : https://journals.openedition.org/abstractairanica/54172

DOI : 10.4000/abstractairanica.54172

ISSN : 1961-960X

Éditeur :

CNRS (UMR 7528 Mondes iraniens et indiens), Éditions de l'IFRI

Référence électronique

Christelle Jullien, "Harald Suermann. "Thomas-Christen von Indien und Rewardashir" », Abstracta Iranica [En ligne], Volume 42-43 | 2021, document 28, mis en ligne le 30 décembre 2021, consulté le 13 décembre 2022. URL : http://journals.openedition.org/abstractairanica/54172 ; DOI : https://doi.org/ 10.4000/abstractairanica.54172

Ce document a été généré automatiquement le 13 décembre 2022.

Tous droits réservés 


\title{
Harald Suermann. „Thomas- Christen von Indien und Rewardashir“
}

\author{
Christelle Jullien
}

\section{RÉFÉRENCE}

Harald Suermann. „Thomas-Christen von Indien und Rewardashir“ in Sh. Talay (ed.).

Überleben im Schatten: Geschichte und Kultur des syrischen Christentums. Beiträge des 10. Deutschen Syrologentages an der FU Berlin 2018. Wiesbaden : Harrassowitz Verlag, 2020, ISBN 9783447114639. (Göttinger Orientforschungen I. Reihe: Syriaca 58), p. 249-258.

1 L'article est publié avec 18 autres contributions dans les actes de la dixième Journée des syriacisants allemands qui fut organisée en 2018 à l'Université libre de Berlin. L'A. y présente une synthèse des données sur les chrétiens dits de saint Thomas, et leurs liens historiques avec la ville de Rew-Ardašīr dans le Fārs. Ce nom fut donné à l'ensemble des chrétiens de diverses confessions établis sur la côte du Malabar, dans le sud-ouest de l'Inde, principalement dans l'État du Kérala. Cette communauté fut placée sous la juridiction de l'Église de Perse, donc du siège patriarcal de Séleucie-Ctésiphon, et sous l'autorité directe du métropolite de Rew-Ardašīr. La tradition de cette communauté a été analysée en détail par J. Kollaparambil en 1992 (The Babylonian Origin of the Southists among the St Thomas Chrisians, [Orientalia Christiana Analecta 241], Rome). G. Gropp avait souligné, à travers l'étude des noms propres de l'inscription de la croix retrouvée à Madras, les dépendances ecclésiales et missionnaires de la région du Fārs et du golfe Persique avec l'Inde („Die Pahlavi-Inschrift auf dem Thomaskreuz in Madras“, Archäologische Mitteilungen aus Iran NF 3, 1970, p. 267-271), ce que l'A. rappelle bien, à la suite des études de B. Varghese ("The So-Called Persian Crosses in South India: State of Research" dans S. Griffith, S. Grebenstein (eds). Christsein in der islamischen Welt: Festschrift für Martin Tamcke zum 60. Geburtstag, Wiesbaden: Harrassowitz Verlag, 2015, p. 389-400) et C. G. Cereti ("Le croci di San Tommaso e la letteratura cristiano in lingue 
medioiraniche" dans M. V. Fontana e B. Genito (a cura di). Studi in Onore di Umberto Scerrato per il suo settantacinquesimo compleanno, Naples, 2003, p. 193-206 ; C. G. Cereti, L. M. Olivieri, J. Vazhuthanapally, "The Problem of the Saint Thomas Crosses and Related Questions", East and West 52, 2002, p. 285-310).

\section{AUTEURS}

\section{CHRISTELLE JULLIEN}

CNRS, CeRMI, Paris 